Tropical Journal of Pharmaceutical Research May 2016; 15 (5): 1077-1081

ISSN: $1596-5996$ (print); 1596-9827 (electronic)

(C) Pharmacotherapy Group, Faculty of Pharmacy, University of Benin, Benin City, 300001 Nigeria.

All rights reserved.

Available online at http://www.tjpr.org

Original Research Article

http://dx.doi.org/10.4314/tjpr.v15i5.25

\title{
Clinical effects of sirolimus treatment in patients with increased serum creatinine levels after renal transplant
}

\author{
Zhen-Hong Pan, Yan-Xuan Zhang*, Jun Fang, Qing-Shan Qu, Xin Jiang and \\ Ming Li \\ Kidney Disease Center, People's Hospital of Zhengzhou, Zhengzhou, Henan, 450003, PR China
}

*For correspondence: Email: zyxzhangpjms@163.com

Received: 7 October 2015

Revised accepted: 7 April 2016

\begin{abstract}
Purpose: To observe the clinical effects of sirolimus (SRL) immunosuppressive therapy in patients with progressively increasing levels of serum creatinine (Scr) after renal transplant.

Methods: In total, 180 patients whose Scr levels had been rising after renal transplant were given an oral calcineurin inhibitor (CNI): either cyclosporine A (CsA) or tacrolimus (FK506). All patients were treated at People's Hospital of Zhengzhou, China, between January 2011 and December 2013, and were given SRL-based conversion treatment. Scr level and glomerular filtration rate (GFR) were observed before and 1, 3, and 6 months after treatment initiation. In addition, liver function, blood glucose, blood lipid levels, rejection reaction incidence, and mortality were recorded to evaluate the effects of SRL.

Results: Scr levels were $116.60 \pm 30.60 \mu \mathrm{mol} / \mathrm{L}$ and $119.00 \pm 24.60 \mu \mathrm{mol} / \mathrm{L}$, and GFR was $70.00 \pm$ $19.70 \mathrm{~mL} / \mathrm{min}$ and $75.90 \pm 15.60 \mathrm{~mL} / \mathrm{min}$, at 3 and 6 months after treatment, respectively. The 3- and 6 month Scr and GFR values were statistically different $(p<0.05)$ compared to pre-treatment levels $(S c r$ : $144.10 \pm 61.70 \mu \mathrm{mol} / \mathrm{L}$ vs and GFR: $59.10 \pm 16.20 \mathrm{~mL} / \mathrm{min}$. Acute rejection (AR) occurred in 20 patients $(13.30 \%)$ within 6 months of treatment initiation, but rejection was reversed with conventional methylprednisolone therapy. Twenty-one patients $(11.70 \%)$ developed lung infections, but all were cured. There were no significant differences in liver function before and after treatment.

Conclusion: SRL-based immunosuppressive therapy is effective in treating patients with increased Scr levels after renal transplant.
\end{abstract}

Keywords: Renal transplant, Serum creatinine, Calcineurin inhibitors, Sirolimus, Acute rejection, Glomerular filtration rate

Tropical Journal of Pharmaceutical Research is indexed by Science Citation Index (SciSearch), Scopus, International Pharmaceutical Abstract, Chemical Abstracts, Embase, Index Copernicus, EBSCO, African Index Medicus, JournalSeek, Journal Citation Reports/Science Edition, Directory of Open Access Journals (DOAJ), African Journal Online, Bioline International, Open-J-Gate and Pharmacy Abstracts

\section{INTRODUCTION}

The extensive application of novel immunosuppressors has led to a dramatic reduction in acute rejection (AR) incidence; however, long-term survival after renal transplant is still not adequate [1,2]. The key factors influencing patient and kidney survival include liver and kidney toxicity, diabetes occurrence, chronic allograft nephropathy, and malignant tumors occurring after transplant [3,4]. Calcineurin inhibitors (CNIs) are currently the most commonly used immunosuppressors in renal transplant patients, and $\mathrm{CNI}$ treatment significantly improves survival rates after transplantation. However, chronic allograft nephropathy (CAN) is caused by renal toxicity, which can be induced by $\mathrm{CNI}$ treatment. The occurrence of CAN due to immunosupressor 
treatment has increased research interest in the transplantation field [5].

Serum creatinine (Scr) levels progressively increase after transplantation in kidneys that enter the decompensation period after CAN. If this decompensation fails to be controlled, transplanted kidney function will be lost. However, the development of new immunosuppressors, such as sirolimus (SRL), make it possible to stop CNI treatment [6]. Treating renal transplant patients with immunosuppressive drugs other than $\mathrm{CNIs}$ has received more attention in recent years. $S R L$, a new generation of powerful immunosuppressor, has less renal toxicity as well as anti-proliferative and anti-tumor effect [7]. SRL treatment represents a potential alternative to CNIs for renal transplant patients. Therefore, the prevention of complications and improvement of long-term survival rates in renal transplant patients has attracted a lot of attention in recent years. Currently, researchers are trying to find an alternative but equally effective treatment to CNIs. In this study, 180 patients who developed CAN after renal transplant at Zhengzhou People's Hospital between February 2011 and December 2013 were treated with SRL conversion therapy.

\section{EXPERIMENTAL}

\section{Subjects}

In total, 180 patients who developed CAN after renal transplant were selected from Zhengzhou People's Hospital between February 2011 and December 2013. Of the 180 cases, 120 were male and 60 were female, with ages ranging from 27 to 49 years (mean, $38.60 \pm 2.40$ years). Conversion treatment started, on average, (46 \pm 10) months after transplantation. Before conversion treatment, 103 cases were given cyclosporine $A(C s A)+$ mycophenolate mofetil $(\mathrm{MMF})+\quad$ prednisone-combined immunosuppressive therapy while 77 cases were given tacrolimus (FK506) + MMF + prednisonecombined immunosuppressive therapy. All patients gave written informed consent; the study has been approved by People's Hospital of Zhengzhou Ethics Committee (approval no. QGYZ201503901) and it followed the guidelines stipulated by the Ethics Committee [8].

\section{Selection criteria}

Patients with the following traits were selected: stable transplant kidney function with Scr level $>140 \mu \mathrm{mol} / \mathrm{L}$ and increased blood pressure and proteinuria 6 months after kidney transplant; patients with $\mathrm{CNI}$-induced hepatotoxicity or abnormal liver function after transplant; patients with diabetes or hyperglycemia after transplant that was controlled with hypoglycemic drugs or insulin; patients who had fibrosis in the transplant kidney confirmed by aspiration biopsy; and patients who had renal tubule atrophy combined with intimal hyperplasia but without AR. Patients who could not undergo immunosuppressive therapy due to a specific disease or financial conditions or who had serum cholesterol over 6 $\mathrm{mmol} / \mathrm{L}$, triacylglycerol over $2 \mathrm{mmol} / \mathrm{L}$, 24-hour proteinuria over $0.80 \mathrm{~g}$, peripheral blood leucocyte counts less than $3.5 \times 10^{9} / \mathrm{L}$, and blood platelet counts less than $80 \times 10^{9} / \mathrm{L}$ were excluded.

\section{Therapeutic schedule}

SRL treatment began upon cessation of $\mathrm{CNI}$ treatment. Patients were given $3-6 \mathrm{mg} / \mathrm{d} \mathrm{SRL}$ on the first day, and then $1-2 \mathrm{mg} / \mathrm{d}$ for 5 - 7 days. After 7 days, blood SRL concentration was maintained at $5-15 \mathrm{ng} / \mathrm{mL}$ by taking SRL orally. SRL concentration was controlled within the therapeutic window range. The dosage of other immunosuppressors remained the same.

\section{Observation indices}

Scr level and glomerular filtration rate (GFR) were detected before, and 1, 3, and 6 months after treatment initiation. AR incidence, infection rate, renal allograft dysfunction rate, and death rate were observed for 6 months after treatment. Liver function, blood glucose, blood parameters, and 24-hour proteinuria were measured before and after treatment initiation to detect adverse reactions.

\section{Statistical analysis}

SPSS 19.0 software was used to analyze the data. All values are expressed as mean \pm standard deviation (SD). Comparison of means was performed using a non-paired t-test. Differences were considered statistically significant at $p<0.05$.

\section{RESULTS}

\section{Analysis of $A R$ and infection after conversion treatment}

Of the 180 cases, 24 (13.30\%) experienced mild AR (level IA - IB) within 6 months of $S R L$ treatment initiation, but all cases were successfully treated with cortical hormones. After $A R$ treatment, all patients had stable renal 
function and no repeat AR. Of the 24 AR cases, 12 had no more AR incidents 6 months after cessation of cortical hormone treatment. No deaths or cases of kidney dysfunction were observed in the 6 months after SRL treatment initiation. Twenty-one patients (11.70\%) developed lung infections, including 12 cases of cytomegalovirus (CMV) infection (accounting for $57.10 \%$ among infection cases), 6 cases of bacterial infection $(28.60 \%)$, and 3 cases of fungal infection (14.30\%); however, all patients were cured by traditional anti-infection treatments.

\section{Changes in Scr and GFR before and after conversion treatment}

Scr levels decreased and GFR increased in the first 6 months of treatment, with significant differences beginning in the 3rd month $(p<0.05)$ (Figure 1).

\section{Changes in liver function and blood glucose}

There were no differences in liver function before and after treatment $(p>0.05)$. Blood glucose levels were normalized after treatment, and this difference was significant $(p<0.05)($ Table 1$)$.

\section{Adverse reactions}

Of the 180 cases, 75 cases $(41.70 \%)$ had increased blood lipid levels after SRL treatment, with 24 cases of increased triglyceride (accounting for $32 \%$ among all cases with increase blood lipids), and 51 cases of increased cholesterol (68\%); In addition, 9 patients (5\%) had decreased leukocyte counts, 6 had $(3.30 \%)$ decreased platelet counts, and 60 (33.30\%) had increased urine protein. Except for blood platelet and leukocyte counts, the other measures described here were significantly different 3 and 6 months after treatment initiation $(p<0.05)$ (Table 2).

\section{DISCUSSION}

Immunosuppressors are an indispensable tool for organ transplantation success. Individual differences and an insufficient understanding of the immune system can affect the development of effective immunosuppressive drugs [9].

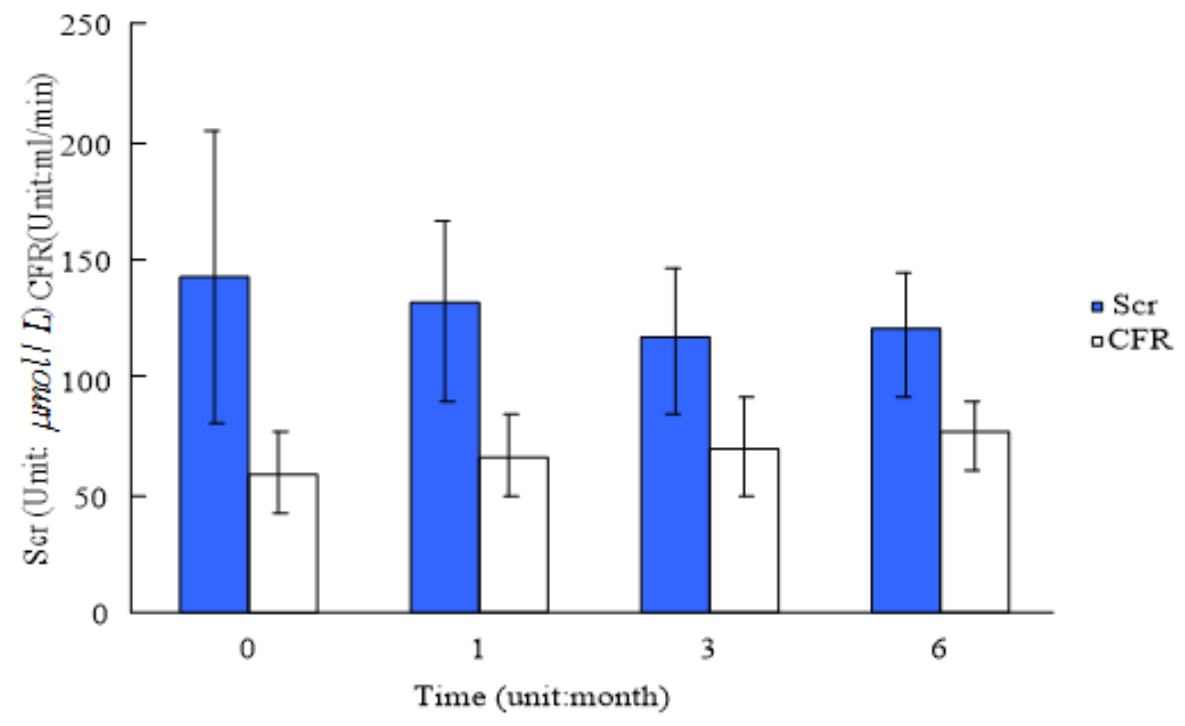

Figure 1: Scr and GFR levels

Table 1: Liver function and blood glucose changes before and after conversion treatment (mean \pm SD)

\begin{tabular}{|c|c|c|c|c|}
\hline Time point & ALT (IU/L) & AST (IU/L) & TBIL ( $\mu \mathrm{mol} / \mathrm{L})$ & Glu (mmol/L) \\
\hline Before conversion treatment & $46.84 \pm 10.04$ & $35.78 \pm 12.15$ & $22.70 \pm 9.30$ & $9.00 \pm 0.90$ \\
\hline $\begin{array}{l}1 \text { month after conversion } \\
\text { treatment }\end{array}$ & $41.80 \pm 18.37$ & $37.83 \pm 17.28$ & $25.30 \pm 5.80$ & $6.70 \pm 0.80^{*}$ \\
\hline $\begin{array}{l}3 \text { months after conversion } \\
\text { treatment }\end{array}$ & $50.15 \pm 13.35$ & $27.00 \pm 19.10$ & $20.30 \pm 5.20$ & $5.90 \pm 1.10^{*}$ \\
\hline $\begin{array}{l}6 \text { months after conversion } \\
\text { treatment }\end{array}$ & $43.13 \pm 11.70$ & $26.00 \pm 15.20$ & $19.20 \pm 4.60$ & $5.60 \pm 0.70^{*}$ \\
\hline
\end{tabular}


Table 2: Comparison of adverse reactions at different time points after $S R L$ treatment initiation

\begin{tabular}{lcccc}
\hline \multirow{2}{*}{ Parameter } & \multirow{2}{*}{ Before } & \multicolumn{3}{c}{ After conversion treatment } \\
\cline { 2 - 5 } & & 1 month & 3 months & 6 months \\
\hline Triglyceride $(\mathrm{mmol} / \mathrm{L})$ & $1.86 \pm 0.87$ & $2.16 \pm 0.96$ & $2.18 \pm 0.90$ & $2.23 \pm 0.89$ \\
Cholesterol $(\mathrm{mmol} / \mathrm{L})$ & $5.12 \pm 1.08$ & $5.81 \pm 1.25$ & $6.17 \pm 1.21$ & $6.21 \pm 1.29$ \\
Leukocyte $\left(\times 10^{\mathrm{y}} / \mathrm{L}\right)$ & $8.87 \pm 2.99$ & $8.28 \pm 2.56$ & $8.06 \pm 2.41$ & $8.08 \pm 2.47$ \\
Blood platelet $\left(\times 10^{\dagger} / \mathrm{L}\right)$ & $224.10 \pm 61.70$ & $223.80 \pm 65.90$ & $217.10 \pm 59.60$ & $214.10 \pm 62.80$ \\
Urine protein $(\mathrm{g} / 24 \mathrm{~h})$ & $0.36 \pm 0.24$ & $0.38 \pm 0.19$ & $0.50 \pm 0.27^{*}$ & $0.52 \pm 0.25^{*}$ \\
\hline
\end{tabular}

${ }^{*} P<0.05$ compared to prior conversion treatment

$\mathrm{CNI}$ treatment is known to have a stable and anti-rejection effect on transplant patients; however, renal toxicity induced by long-term CNI treatment is a significant issue and occurs in the majority of $\mathrm{CNI}$-treated patients. Nankivell et al [10] found that $68 \%$ of patients with CNI-induced renal toxicity had CAN 1 year after transplant; 62 $\%$ of patients treated with FK506 developed CAN 2 years after transplant; and $72 \%$ of patients treated with CsA developed CAN 2 years after transplant. Therefore, reducing or avoiding CNI treatment can lower the incidence of CAN and improve long-term survival rates in transplant patients, as well as increasing transplant organ survival.

SRL, a new generation of immunosuppressor, is characterized by reduced renal toxicity. SRL is mainly metabolized in the liver and gastrointestinal tract through the cytochrome P450 system, and over $91 \%$ of the metabolite product is expelled through the gastrointestinal tract, and a further $2 \%$ is expelled through the skin $[11,12]$. SRL prevents the transition from $\mathrm{G} 1$ phase to $S$ phase in $T$ lymphocytes, and can therefore prevent interleukin-2 (IL-2) receptor binding and Tc and Td cell sensitization [13]. In addition, previous studies have shown that SRL also has anti-proliferative and anti-tumor effects $[14,15]$ SRL can be an alternative treatment to $\mathrm{CNI}$ for patients who develop tumors or CAN after rental transplant.. In this study, Scr levels decreased and GFR increased in the 6 month period after SRL treatment initiation. Overall, $\mathrm{SRL}$ was effective at treating CAN.

Risk is inevitable when using a new immunosuppressor for conversion treatment. First, the occurrence of $\mathrm{AR}$ and excessive immunosuppression should be noted during treatment [16,17]. In this study, 24 cases experienced AR within 6 months of SRL treatment initiation, and this appeared to correlate with the withdrawal of FK506, unstable blood SRL concentration, absorption differences, and liver metabolism [18]. Lung infections usually occur when immunosuppression is excessive. Of the 180 cases, 21 developed lung infections within 6 months of conversion treatment initiation; however, all recovered after traditional anti-infection treatment and SRL dosage adjustment. This indicates that insufficient and excessive immunosuppression can be avoided during conversion treatment with SRL.

In addition, there were no remarkable differences in liver function after conversion therapy initiation, and blood glucose levels were normalized, suggesting that SRL had little influence on blood glucose levels. Adverse reactions included hyperlipidemia, proteinuria, and myelosuppression. In this study, 75 of 180 cases $(41.70 \%)$ had increased blood lipid levels after conversion treatment, with significant differences beginning 3 months after treatment initiation.

The increased lipid levels were found to be dosedependent; therefore, blood lipid levels could be managed by decreasing the dose of SRL. Forty patients $(33.30 \%)$ experienced increased proteinuria, with significant differences beginning 3 months after treatment initiation. Although all patients continued SRL treatment despite proteinuria and its unknown mechanism of action, this may be a concern for the future potential treatment with SRL.

\section{CONCLUSION}

The findings show that renal function improved after conversion treatment, indicating that SRL was more effective than FK506. SRL-based immunosuppressive therapy is effective and safe for treating FK506-induced Scr increases; however, the optimal dose and treatment plan for $S R L$ is yet to be determined.

\section{ACKNOWLEDGEMENT}

The authors sincerely thank all who supported this work.

\section{CONFLICT OF INTEREST}

No conflict of interest associated with this work. 


\section{CONTRIBUTION OF AUTHORS}

We declare that this work was done by the authors named in this article and all liabilities pertaining to claims relating to the content of this article will be borne by the authors.

\section{REFERENCES}

1. Lin J, Tang $Y W$, Du LD, Tian $Y$, Guo HB, Xie ZL, Sun W, Zhang $L$. Clinical observation of sirolimus instead of calmodulin inhibitors in patients with chronic renal allograft dysfunction. Chin J Surg 2008; 46(1): 70-71.

2. Zaghla $H$, Selby RR, Chan LS, Kahn JA, Donovan JA, Jobbour N, Genyk Y, Mateo R, Gagandeep S, Sher LS et al. A comparison of sirolimus vs. calcineurin inhibitorbased immunosuppressive therapies in liver transplantation. Aliment Pharmacol Ther 2006; 23(4): 513-520.

3. Asberg A, Hartmann A, Fjeldsa $E$, Holdaas $H$. Atorvastatin improves endothelial function in renaltransplant recipients. Nephrol Dial Transplant 2001; 16(9): 1920-1924.

4. Ojo AO, Held PJ, Port FK, Wolfe RA, Leichtman $A B$, Young EW, Arndorfer J, Christensen L, Merion RM. Chronic renal failure after transplantation of a nonrenal organ. N Engl Med 2003; 349(10): 931-940.

5. Ni XJ, Zheng SL, Yang YR, Xia P, Chen BC, Wu CZ, Sun $Y N$, Cai $Y$. Three immunosuppressant conversion protocols in kidney transplant recipients with creeping creatinine. Chin J IntegratTradit West Nephrol 2008; 9(11): 974-977.

6. Bumbea V, Kamar $N$, Ribes D, Esposito L, Modesto A, Guitard J, Nasou G, Durand D, Rostaing L. Long-term results in renal transplant patients with allograft dysfunction after switching from calcineurin in inhibitors to sirolimus. Nephrol Dial Transplant 2005; 20(11): 2517-2523.

7. Tomasoni S, Remuzzi G, Beniqni A. Allograft rejection: acute and chronic studies. Contrib Nephrol 2008; 159: 122-134.

8. Medical ethical principles of study for human body of People's Hospital of Zhengzhou.
9. Watson CJ, Firth J, Williams PE, Bradley JR, Pritchard N, Chaudhry A, Smith JC, Palmer CR, Bradley JA. A randomized controlled trial of late conversion from $C N I-$ based to sirolimus-based immunosuppression following renal transplantation. Am J Transplantation 2005; 5(10): 2496-2503.

10. Nankivell BJ, Borrows RJ, Fung CL, O'Connell PJ, Allen $R D$, Chapman JR. The natural history of chronic allograft nephropathy. N Engl J Med. 2003; 349(24): 2326-2333.

11. Jia RP, Ji SM. Research progress of minimizing the side effects of immunosuppression in renal transplant recipients. J Med Postgraduate 2005; 18(7): 642-646.

12. Dean PG, Grande JP, Sethi S, Park WD, Griffin MD, Cosio FG, Larson TS, Stegall MD. Kidney transplant histology after one year of continuous therapy with sirolimus compared with tacrolimus. Transplantation 2008; 85(8): 1212-1215.

13. Stallone $G$, Infante $B$, Schena $A$, Battaglia $M$, Ditonno $P$, Loverre A, Gesualdo L, Schena FP, Grandaliano G. Rapamycin for treatment of chronic allograft nephropathy in renal transplant patients. J Am Soc Nephrol 2005; 16(12): 3755-3762.

14. Saunders RN, Bicknell GR, Nicholson ML. The impact of cyclosporine dose reduction with or without the addition of rapamycin on functional, molecular, and histological markers of chronic allograft nephropathy. Transplantation 2003; 75(6): 772-780.

15. Diekmann F, Campistol JM. Conversion from calcineurin inhibitors to sirolimus in chronic allograft nephropathy: benefits and risks. Nephrol Dial Transplant 2006; 21(3): 562-568.

16. Huo W. Sirolimus-induced adverse reactions following kidney transplantation. J Clin Rehabilitative Tissue Engineering Res 2010; 14(31): 5825-5828.

17. Cravedi $P$, Ruggenenti $P$, Remuzzi G. Sirolimus for calcineurin inhibitors in organ transplantation: contra. Kidney Int 2010; 78(11): 1068-1074.

18. Ji SM, Yin G, Chen JS, Yin LP, Sha GZ, Zhou H, Li LS. Combined regime of rapamycin and cyclosporine in the prevention of acute rejection in renal allograft recipients. Chin J Nephrol Dialy Transplant 2003; 12(2): 132-135. 